\title{
TECNOLOGIAS NA EDUCAÇÃO: INCLUSÃO DIGITAL DOS PROFESSORES DA REDE ESTADUAL A PARTIR DA IMPLEMENTAÇÃO DO PROGRAMA TABLET EDUCACIONAL
}

\author{
Cíndia Rosa Toniazzo Quaresma, PPGTER/UFSM, cindiaquaresma.10@gmail.com \\ Ilse Abegg, PPGTER/UFSM, ilse.abegg@,ufsm.br \\ Solange Beatriz Billig Garcês, Pedagogia/UNICRUZ, sbgarces@hotmail.com \\ Rosane Rodrigues Felix, Pedagogia/UNICRUZ, felix@comnet.com.br
}

\begin{abstract}
Resumo
Este trabalho teve como objetivo investigar o processo da inserção do tablet em escolas públicas a partir do Programa Tablet Educacional. A pesquisa foi realizada na Escola Estadual de Educação Básica Margarida Pardelhas, da cidade de Cruz Alta-RS, tendo como sujeitos de pesquisa os professores do Ensino Médio que receberam a ferramenta. Buscou-se acompanhar o processo de inserção do tablet, a fim de verificar as formas de apropriação da ferramenta, as possibilidades pedagógicas e as estratégias para superação das dificuldades encontradas. Verificou-se que a fluência tecnológica dos professores e o conhecimento prévio sobre o tablet influenciaram na apropriação da ferramenta. A inclusão digital é potencializada a partir da inserção da ferramenta e das formações. $\mathrm{O}$ uso do tablet possibilitou o suporte para o trabalho do professor. As aprendizagens colaborativas (redes de aprendizagem) entre o grupo de professores foram essenciais para a evolução na apropriação da ferramenta. As análises demandam novas discussões acerca da inclusão digital de professores através da inserção das tecnologias na escola, mas especialmente a partir da formação continuada dos professores em tecnologias educacionais.
\end{abstract}

Palavras-chave: Políticas Educacionais. Formação Docente. Inclusão Digital. Tecnologias Educacionais

\section{TECHNOLOGY IN EDUCATION: TEACHERS DIGITAL INCLUSION NETWORK STATE FROM THE IMPLEMENTATION OF EDUCATIONAL PROGRAM TABLET}

\begin{abstract}
This study aimed to investigate the process of inserting the tablet in public schools from the Program Educational Tablet. The research was conducted at the State School of Basic Education Margaret Pardelhas, the city of Cruz Alta-RS having as research subjects of secondary school teachers who received the tool. We attempted to follow the process of inserting the tablet in order to verify the forms of appropriation of the tool, the pedagogical possibilities and strategies for overcoming difficulties. It was found that the technological fluency of teachers and previous knowledge about the tablet influenced the appropriation of the tool. Digital inclusion is enhanced with the insertion tool and formations. The use of tablet enabled support for the work of teachers. The collaborative learning (learning networks) between the group of teachers were essential to the evolution in the appropriation of the tool. The analyzes require further discussions on digital inclusion of teachers through the integration of technology in the school, but particularly from the continuing education of teachers in educational technology.
\end{abstract}


Keywords: Educational Policy; Teacher Training; Digital Inclusion; Educational Technologies

\title{
Introdução
}

A escola tem se desafiado a integrar novas práticas pedagógicas por conta das transformações do mundo contemporâneo. Estamos vivendo no contexto de uma sociedade que exige aprendizagens constantes, sendo que o professor deve estar disposto a rever conceitos, superar paradigmas, (re) construir concepções, uma vez que a evolução das tecnologias tem impactado as relações entre aquele que ensina e aquele que aprende, onde ambos, professor e estudante estão em constante interlocução. Pois como coloca Freire (1996, p. 12) "Aprender precedeu ensinar, [...] ensinar se diluía na experiência realmente fundante de aprender”. Neste contexto, (Lévy, 2004, p. 7), nos coloca que:

\begin{abstract}
Novas maneiras de pensar e de conviver estão sendo elaboradas no mundo das telecomunicações e da informática. As relações entre os homens, o trabalho, a própria inteligência dependem, na verdade, da metamorfose incessante de dispositivos informacionais de todos os tipos. Escrita, leitura, visão, audição, criação, aprendizagem são capturados por uma informática cada vez mais avançada.
\end{abstract}

Assim, como forma de acompanhar o ritmo das mudanças tecnológicas, o Governo Brasileiro, através do programa Proinfo, Programa Nacional de Tecnologia Educacional (Brasil, 2009, online), tem oferecido suporte através da instrumentalização das escolas e professores por entender que as tecnologias "promovem novas estratégias pedagógicas através do uso de conteúdos digitais". Vinculada a esse programa A Secretaria da Educação do Estado do Rio Grande do Sul, desenvolve o programa RS MAIS DIGITAL - Projeto Província de São Pedro, em parceria com o FNDE, através do qual distribui Tablets aos professores do Ensino Médio, oferecendo uma tecnologia móvel que significa uma maior mobilidade e possibilidade de acesso. (Rio Grande do Sul, 2010)

Esse processo significa novos desafios a serem vencidos pelas escolas e professores na busca da qualificação do processo ensino-aprendizagem. Como coloca Alonso (2008, p. 2) "Pretende-se que a incorporação das TIC pelas escolas seja elemento catalizador de mudanças significativas na aprendizagem dos estudantes."

As Tecnologias da Informação e Comunicação (TIC) apresentam, também, impactos importantes na Inclusão Digital, na busca da correção das desigualdades através da possibilidade de acesso no âmbito escolar, sendo este um dos objetivos do Projeto Proinfo Integrado desenvolvido pelo Ministério da Educação. Nesta concepção os professores devem ter prioridade quanto ao acesso às ferramentas e recursos tecnológicos para que possam implementar novas propostas metodológicas, a partir de práticas inovadoras. Para isso é preciso estar aberto a novas aprendizagens. Como coloca Freire (1996, p. 12) o professor enquanto ensina também aprende, pois "ensinar inexiste sem aprender", é um caminho de mão dupla.

Trata-se de não apenas inserir os artefatos tecnológicos no cotidiano escolar, mas verificar de que forma estão contribuindo para qualificar a educação e quais impactos têm causado. Remete-se então, a um novo paradigma, a concepção da 
aprendizagem cooperativa ou colaborativa mediada por computador, a possibilidade de aprender mediado por redes, "As redes funcionam como estruturas cognitivas interativas [...] e pela interferência possível do conhecimento que outras pessoas construíram ou estão construindo .[...] o aprendente pode assumir o papel de verdadeiro gestor dos seus processos de aprendizagem." (Assmann, 2000, p. 11) Para Castells (2006, p. 566) "Rede é um conjunto de nós interconectados", desta forma o avanço tecnológico proporcionou um aumento exponencial do efeito de rede, modelando a sociedade atual, a sociedade da informação e do conhecimento. Sobre as redes Kesnki (2007, p.39) também coloca que não há uma liderança e funcionam articulando diversos elementos em movimento, podem ser pessoas ou organizações englobadas na internet.

Portanto é fundamental que ocorra um acompanhamento sobre a inserção destas ferramentas no cotidiano do professor, buscando verificar de que forma estes recursos vêm influenciar e contribuir para o trabalho pedagógico do professor. Bem como, conhecer de que forma os docentes estão recebendo este novo desafio. Quais relações o professor estabelece ao mediar suas práticas docentes pelo Tablet, ou outros recursos e ferramentas, para a Inclusão Digital e Exercício da Cidadania. Na busca de aprofundar o estudo sobre esta transformação, que vem ocorrendo no cotidiano das escolas, com a inserção, especialmente dos Tablets Educacionais é que realizamos esta pesquisa.

\section{Metodologia}

A pesquisa realizada foi do tipo participativa e teve como sujeitos da pesquisa os docentes do Ensino Médio que receberam o tablet, um total de 15 professores. Foram realizados dois encontros de formação, do qual participaram todos os professores. Utilizaram-se fichas de observação para registrar os aspectos relacionados à pesquisa durante os encontros.

Além disso, no segundo encontro foi utilizado um questionário, sendo que, do total, 10 participantes responderam. Os instrumentos foram elaborados pela própria pesquisadora e validados por três especialistas da área. Os dados coletados foram analisados e interpretados de forma qualitativa através de categorias de análise a partir de uma matriz, conforme os objetivos específicos e quando possível, esses dados foram quantificados, utilizando-se estatística descritiva. A matriz analítica era composta por: inserção de tablet no cotidiano escolar; fluência tecnológica; aprendizagem mediada por tecnologias em rede; inclusão digital. Os resultados e discussões são apresentados abaixo.

\section{Resultados e Discussões}

\section{O processo de inserção do tablet no cotidiano escolar}

O projeto acerca da inserção dos tablets na escola acontece em virtude do envolvimento dos professores do ensino médio no programa Província de São Pedro do Governo Estadual. Atuam no ensino médio da escola 34 professores, mas somente 16 receberam o tablet, dentre eles 15 docentes e 1 coordenador pedagógico. O critério para receber o tablet foi, ser professor efetivo do quadro do magistério (concursado) e participar da formação inicial.

A partir da formação inicial, que aconteceu nos dias 25 e 26 de abril, na Sala Digital da escola e foi realizada pela Secretaria da Educação - SEDUC, iniciou-se o acompanhamento da inserção dos tablets na escola. Neste momento os professores receberam seus tablets, assinaram a documentação e receberam as primeiras 
orientações. Após esse período procurou-se manter contato com os professores durante as atividades cotidianas da escola, assessorando nas dificuldades e dúvidas, bem como através do grupo criado numa rede social para trocas e discussões sobre diversos temas, dentre eles a mediação das práticas pedagógica pelo tablet.

Realizou-se um segundo encontro de formação no dia 06 de junho a fim de compartilhar ideias e experiências, promovendo uma aprendizagem colaborativa através do grupo de professores que recebeu o tablet, e desta forma aperfeiçoar a sua utilização para as atividades docentes na escola. Buscou-se também verificar as dúvidas e dificuldades encontradas até o momento que limitaram o uso da ferramenta, bem como socializar casos de sucesso na utilização do tablet e os recursos por ele oferecidos. Para que possamos estabelecer outras formas de trabalho e formação de professores para a mediação das práticas escolares com as tecnologias educacionais.

Neste encontro os professores também foram convidados a participar de uma pesquisa sobre a inserção do tablet, receberam um questionário para responderem. Durante os encontros e o período de uso do recurso, foram registradas informações sobre o uso do tablet na escola em fichas de observação. Também, foram utilizadas duas fichas de observação: uma na primeira formação e recebimento do tablet e a segunda no outro encontro de formação e socialização de experiências.

\section{A importância da fluência tecnológica do professor na apropriação das ferramentas}

A inserção das tecnologias na escola se dá a partir de programas governamentais que oferecem os recursos e ferramentas tecnológicas aos professores, como no caso dos tablets educacionais, e também proporcionam a formação continuada. $\mathrm{Na}$ primeira formação os professores estavam inseguros e ansiosos, mas ao longo dos trabalhos foram se envolvendo e descobrindo que eram capazes de manusear o tablet. Ficaram motivados com as novas aprendizagens, interagiram, trocaram informações e aprenderam de forma colaborativa. Demonstraram disposição para aprender e envolveram-se com as possibilidades de aprender algo novo.

No segundo momento de formação proposta pela prof ${ }^{a}$ da sala digital participaram 14 professores. Destaca-se que os professores estavam dispostos a aprender juntos, trocando informações, conhecimentos e ideias, na tentativa de superar as dificuldades e os desafios iniciais no uso e manuseio do tablet. Evidenciou-se que os professores com maior fluência tecnológica haviam evoluído mais, descoberto aplicativos e utilizado o tablet no seu cotidiano para pesquisar, organizar sua agenda, instalar novos aplicativos. Um dos professores criou um grupo no Google+ (Professores Conectados) com o intuito de socializar as aprendizagens e dicas, convidando a todos para participar. Um grupo na rede social também foi criado pela prof ${ }^{\mathrm{a}}$ da sala digital com o mesmo objetivo, mas a interação foi restrita em ambos espaços.

As formações se fazem cruciais para a evolução dos professores pela oportunidade de troca de informações e conhecimentos. Desta forma, comparando a reação dos professores em relação aos dois encontros realizados, no segundo encontro constatou-se que alguns estavam decepcionados pela dificuldade que tiveram ao tentar usar o tablet sozinhos, pois não tiveram muito sucesso. Por outro lado alguns que inicialmente não queriam nem aceitar o tablet mudaram sua posição e aprenderam muito durante este período, demonstrando vontade e motivação para continuar apropriando-se da ferramenta. O que é muito positivo!

Em torno de 5 professores com maior familiaridade com as tecnologias e que já possuíam conhecimento em utilizar o tablet, o sistema android, tiverem maiores progressos e puderam compartilhar informações e novas dicas e orientações aos colegas. Constatou-se que $50 \%$ dos professores conheciam o tablet e $40 \%$ conhecia um 
pouco sobre sistema operacional android. A outra metade desconhecia o tablet, somente sabia da sua existência no mercado tecnológico.

É evidente a influência do conhecimento prévio sobre o uso do tablet e a fluência tecnológica do professor para a apropriação da ferramenta. Os posicionamentos dos professores indicam que conhecer o tablet e dominar de forma básica a informática facilitou a apropriação da ferramenta. Percebe-se isso pelas seguintes falas:

"Foi mais fácil assimilar os conhecimentos ofertados na formação para uso do tablet"(P4);

"O fato de conhecer o tablet facilitou muito o uso em sala de aula"(P9);

Aqueles com menor fluência tecnológica e desconhecimento sobre o tablet enfrentaram mais dificuldades, o que os motivou à busca de estratégias de superação e conhecimento do "novo", como se observa nas falas abaixo:

"Não saber utilizar o tablet influenciou, pois é um universo desconhecido, novo, e todo o tempo, com o uso contínuo estou sempre descobrindo novidades";(P6)

"O fato de não conhecer dificultou um pouco, mas ao mesmo tempo estimulou-me a mexer mais para descobrir todas as possibilidades de uso".(P8)

Portanto, educação e tecnologia são indissociáveis como coloca Kenski (2007, p 43): "A forma de utilização de alguma inovação, seja ela um tipo novo de processo, produto, serviço ou comportamento, precisa ser informada e aprendida." O professor necessita adaptar-se ao contexto da sociedade tecnológica buscando apropria-se dos recursos disponíveis aproximando-os da sua prática pedagógica.

\section{Descobertas e Construções na Utilização do Tablet Pelo Professor: uma relação com as possibilidades de aprendizagens mediadas por recursos educacionais em rede}

Os momentos seguintes à formação foram marcados pela exploração do tablet, na busca de aprender suas funcionalidades, o uso da internet para acessar as redes sociais, e-mail, ferramentas e recursos disponíveis através de aplicativos instalados no tablet. Constatou-se que em torno de três professores utilizaram o tablet em sala de aula, usando-o como apoio para suas aulas, como uma ferramenta de armazenamento de materiais pedagógicos para a aula, pesquisa na internet durante as aulas e registro de atividades através de fotos. Foram observadas algumas dificuldades em apropriar-se do tablet, seus aplicativos e o sistema operacional android. $\mathrm{O}$ acesso à internet também ficou prejudicado na escola pela falta de sinal em todas as salas e a velocidade muito lenta.

Os relatos dos professores demonstram que o uso do tablet como ferramenta de pesquisa contribuiu para suas atividades, e também no apoio as atividades em sala de aula, pois destacam que "o tablet funciona como "um "caderno arquivo" da tua aula, onde você marca, acompanha em que momento parou em cada turma. Aos poucos vai explorando o uso para aprender e descobrir suas possibilidades".(P8)

Alguns professores elaboram seus planos de aula no tablet, o que facilita e reduz a quantidade de materiais a serem deslocados para a sala de aula, conforme relato: "Os meus planos de aula preparo no computador e transfiro para o tablet e nele faço as modificações necessárias. Outro ponto importante é a grande variedade de livros e imagens que ele armazena."(P9)

Também é importante destacar que o tablet dispõe de materiais e aplicativos já instalados, e que contribuem para o trabalho do professor, como coloca um dos pesquisados: "O material complementar trazido no tablet ampliam a variedade de 
exemplos e exercícios, mas não proporcionam, necessariamente uma interação com os estudantes .’(P10)

Temos então um novo aspecto a considerar, as interações propiciadas pelo uso da ferramenta, neste aspecto a maioria dos professores coloca que ainda não foi utilizada nenhuma ferramenta com a participação direta do estudante.

Também ficou evidente a maior facilidade e evolução dos professores com melhor fluência tecnológica, desta forma ao professor:

\begin{abstract}
Não basta adquirir a máquina, é preciso saber utilizá-la, a descobrir as melhores maneiras de obter da máquina auxílio nas necessidades de seu usuário. É preciso buscar informações; realizar cursos, pedir ajuda aos mais experientes, enfim, utilizar os mais diferentes meios pra aprender a se relacionar com a inovação e ir além, começar a criar novas formas de uso e, daí, gerar outras utilizações. Essa novas aprendizagens, quando colocadas em prática, reorientam todos os nossos processos de descobertas, relações, valores e comportamentos. (Kenski, 2007, p 44)
\end{abstract}

Este fato instiga a reflexão acerca da formação necessária para que o professor passe a utilizar ferramentas tecnológicas como o tablet. Ressalta-se que o professor precisar ser estimulado e orientado para utilizar recursos e ferramentas tecnológicas presentes no seu cotidiano e na "vida" dos estudantes. Pois, "cada vez mais, é preciso que haja uma nova escola, que possa aceitar o desafio da mudança e atender às necessidades de formação e treinamento em novas bases." (Kenski, 2007, p 51).

É extremante importante oferecer momentos de formação dentro da escola, com a possibilidade de compartilhar experiências entre os seus pares, para que a escola possa construir sua própria proposta de uso das tecnologias, numa perspectiva de ensinar e aprender abarcando novas e diversas oportunidades de construção e compartilhamento de informação e conhecimentos.

\title{
Primeiros passos: a inclusão digital, a construção da cidadania e a formação de professores
}

Para que ocorra a inserção efetiva das tecnologias na escola a formação de professores e a inclusão digital são elementos essenciais. Pois, para que o professor possa aprimorar seus conhecimentos em tecnologias educacionais e usá-la de forma eficaz como ferramenta pedagógica é essencial que a "inclusão digital" inicie pelo professor. Para reforçar a lógica inclusão digital na escola, especialmente oferecendo aos professores estas possibilidades, Teixeira (2010, p 40) coloca que é preciso que ocorra a

[...] ampliação do conceito de inclusão digital para uma dimensão que privilegie a forma de acesso, e não somente o acesso em si, e que tenha como base e finalidade a construção e a vivência de uma cultura de rede como elemento fundamental para o exercício da cidadania na sociedade contemporânea.

É também importante destacar que a cidadania representa a equidade de oportunidades, e um movimento de alavancar práticas que se utilizem das tecnologias como forma de garantir que o indivíduo aproprie-se das tecnologias também como 
inclusão social, alicerçada em uma concepção de democracia e cidadania, tendo o conceito de cidadania alicerçado nas colocações de Canclini (2005, p. 103) como a conquista dos

[...] mínimos competitivos em relação a cada um dos recursos capacitadores para participar da sociedade: trabalho, saúde, poder de compra e outros direitos socioeconômicos, junto com a ",esta" educativa, informacional, de conhecimentos, ou seja, as capacidades que podem ser usadas para conseguir melhor trabalho e maiores rendas (grifo em itálico nossos).

Embora a inclusão digital seja algo presente e necessário para a evolução do uso das tecnologias, nem todos os professores demonstram estabelecer relações entre os programas governamentais de inclusão digital e a sua própria inclusão neste contexto. Percebe-se isso pelas seguintes falas:

"O estudante já domina a tecnologia, mais alguns professores não. Por isso, ainda não percebo a inserção do tablet numa perspectiva de inclusão digital de forma mais abrangente."(P3)

Entretanto a maioria dos professores indica a inclusão digital a partir do acesso à internet e outros materiais didáticos. Colocam que o tablet apoia o trabalho do professor em sala de aula, possibilitando a pesquisa e solução de problemas imediatos, sanando dúvidas dos estudantes.

"Quanto aos professores, sinto que foi um salto bem grande, pois trocando informações podemos estar cada vez mais preparados para utilizar essa tecnologia de forma pedagógica." (P4)

"É uma ferramenta que amplia horizontes"(9);

"O uso do tablet pelo professor está trazendo, muitos professores para um mundo ainda novo"(P10).

Esse contexto indica que ainda temos um vasto caminho a construir para a inclusão digital dos professores, mas os próprios professores precisam reconhecer-se inseridos no processo de inclusão digital, isto é algo que vai se construindo aos poucos, especialmente entre aqueles que tiveram oportunidade de conhecer essas ferramentas através desse projeto.

\section{Superando as dificuldades: estratégia e soluções}

A maior dificuldade percebida foi de ordem técnica, de apropriação das ferramentas e aplicativos do tablet e o acesso à internet, lentidão que inviabiliza a navegação. Segundo os professores, vários recursos instalados no tablet que despertaram seu interesse não puderam ser utilizados, pois não carregavam, uma vez que são online, precisam do acesso à internet. A conexão HDMI disponível no tablet que possibilita o uso do projetor multimídia não funcionou, problema já constatado na primeira formação.

A falta de familiaridade com o sistema e o tempo restrito foram impedimentos para a evolução dos professores, bem como as novas aprendizagens que demandam o uso das ferramentas e aplicativos. As dificuldades forma evidenciadas pelas seguintes falas:

"Sim, as normais. Para salvar arquivos, para saber onde salvar e trabalhar no

Office, mas aos poucos foram sanadas."(P1) 
inclusão social, alicerçada em uma concepção de democracia e cidadania, tendo o ordem técnica também não tenho conseguido acessar internet."(P5).

Mas, todos os professores buscaram estratégias para superar as dificuldades, como auxílio na sala digital, as trocas de informações entre os colegas na escola e nos grupos criados na rede social e no Google+ e também a busca de ajuda com outras pessoas com maior conhecimento sobre a ferramenta. Observa-se através das colocações:

"Sempre to[estou] buscando aplicativos para verificar a eficácia. Na dúvida busco auxílio com a profe labor de informática." (P1)

"Busquei ajuda com os colegas e com a profe da sala digital."(P7)

Também se salientou a importância de "mexer" no tablet, explorar, o ir e vir na descoberta das suas funcionalidades. Verifica-se a partir da fala:

"A estratégia para sanar as dificuldades foi manusear, mexer bastante, até aprender. Solicitei ajuda da profe Cíndia e da minha filha."(P6)

Então, destaca-se a aprendizagem colaborativa como um fator essencial na superação das dificuldades encontradas.

\section{Conclusão}

Conclui-se que a fluência tecnológica do professor e o conhecimento prévio da ferramenta e seu sistema foram fundamentais para a apropriação da ferramenta. Desta forma, permitiu que o tabelt fosse usado como suporte para o trabalho pedagógico do professor, através do armazenamento de materiais necessários para o desenvolvimento das aulas, bem como o registro dos planos de aula e o acesso à internet, possibilitando um avanço e uma inovação para o contexto de sala de aula.

A inserção do tablet também representa a inclusão digital do professor, para alguns isso é claro e importante, pois percebem-se como parte desse processo. Outros ainda sentem-se excluídos, à medida que os estudantes têm maior domínio das tecnologias. Durante esse processo dificuldades surgiram e foram superadas através das redes de aprendizagem colaborativa. $\mathrm{O}$ compartilhamento e troca de informações e conhecimentos entre os professores foi determinante para a evolução e apropriação da ferramenta. Este trabalho não tem a pretensão de solidificar todas as verdades, mas ampliar as discussões acerca da inserção do tablet, seu potencial pedagógico e a inclusão digital do professor, pautada na lógica da sociedade da informação.

\section{Referências Bibliográficas}

ALONSO, Katia Morosov. Tecnologias da informação e comunicação e formação de professores: sobre rede e escolas. Disponível em:

$<$ http://www.scielo.br/scielo.php?pid=S0101-73302008000300006\&script=sci_arttext $>$. Acesso em 10 jun. 2013.

ASSMANN, Hugo. A metamorfose do aprender na sociedade da informação. 2000. Disponível em: <www.scielo.br/pdf/ci/v29n2/a02v29n2.pdf.>. Acesso em: 15 abr. 2013. 
BRASIL: Ministério da Educação - Plano de Desenvolvimento da Educação. 2009. Disponível

em: $<$ http://portal.mec.gov.br/pde/index.php?option=com_content\&task=view\&id=153

\&Itemid $=256>$. Acesso em 18 abr. 2013.

.PROINFO .Disponível

em:

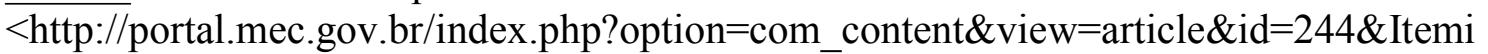
$\mathrm{d}=462$.> Acesso em: 20 abr. 2013.

CANCLINI, Nestor G. Diferentes, Desiguais e Desconectados: mapas da interculturalidade. Tradução Luiz Sérgio Henriques. 2.ed. Rio de Janeiro : UFRJ, 2005.

CASTELLS, M. A Sociedade em REDE: A Era da Informação: Economia, Sociedade e Cultura. Paz e Terra, 2006. V. 1.

FREIRE, Paulo. Pedagogia da Autonomia: saberes necessários à prática educativa. São Paulo, SP. Paz e Terra, 1996.

KENSKI, Vani Moreira. Educação e Tecnologias: O novo ritmo da informação. 2.ed. Campinas, SP: Papirus, 2007.

LÉVY, Pierre. As Tecnologias da Inteligência: O Futuro do Pensamento na Era da Informática. São Paulo: Ed. 34, 2004.

RIO GRANDE DO SUL. SECRETARIA DA EDUCAÇÃO DO ESTADO DO RIO GRANDE DO SUL. CATE- Central de Apoio Tecnológico da Educação. 2010. Disponível em: $<$ http://www.educacao.rs.gov.br/pse/html/cate.jsp?ACAO=acao9. $>$ Acesso em: 26 abr. 2013.

. CATE- Central de Apoio Tecnológico da Educação. Projeto Província de São Pedro - RS MAIS DIGITAL. Disponível em: $<$ http://www.educacao.rs.gov.br/pse/html/proj_provincia.jsp.>. Acesso em: 29 abr. 2013. Acesso em 20 abr. 2013.

TEIXEIRA, Adriano Canabarro. Inclusão Digital: Novas perspectivas para a informática educativa. Ijuí-RS: Ed. UNIJUI, 2010. 